\title{
III. Beiträge zur radicalen Heilung der Hernien
} von

Dr. Carl Sehwalbe,

practischem Arzte zu Weinheim a. Bergstrasse.

In vorigen Jahre hatte ich in dieser Zeitschrift einige Falle von radicaler Heilung kleiner Hernien durch subcutane Alcoholinjection in die Umgebung der Bruchpforte veröffentlicht.

Ich lasse jetzt einige Beispiele von der Heilung grosser Leistenbrïche durch dieselbe Methode folgen.

1. Johannes Schilling, Maurer, 44 Jahre, Mörlenbach. Seit $\%$ Jahre beginnender innerer Leistenbruch rechts; Bruchplorte fur den Zeigefinger durchgängig; Patient trägt ein Bruchband. Es wurden Injectionen von 70 Proc. Alcohol gemacht, ein oder zwei Spritzen in einer Sitzung, am 27. Mai, 11., 18. u. 24. Juni, 13., 23. u. 30. Juli, 6., 12. u, 21. August, 1., 14. u. 26. October, 26. November 1876. Im August war vollständige Heilung eingetreten. Die Oeffnung des Kanals war vollständig geschlossen, man fuihlt aber noch den scharfen Rand der Pforte. Beim stärksten Husten u. s. w. kein Austreten, keine Schmerzen. 7. Mai 1877 vollständig geheilt geblieben.

2. Adam Steckler, 40 Jahre, Schmied, Mörlenbach. Beiderseits beginnender Leistenbruch; links Bruchpforte für den Zeigefinger zugänglich; Patient trägt ein Bruchband, hat aber beim Schmieden viel Beschwerden. Es wurden Injectionen gemacht am 5., 11., 18., u. 25. Juni, 9., 16. u. 23. Juli, 6., 13. u. 26. August, 3. 17. September, 1., 15., 22. u. 28. October, 5., 19. November 1876 . Bruchpforten geschlossen; keine Oeffnung zu finden; beim stärksten Husten kein Austritt. 1. Februar 1877 keine Bruchpforte zu finden. Beim Husten u. s. w. kein Austritt, keine Schmerzen. lch hatte Patienten empfohlen beim Schmieden das Band anzubehalten; ich weiss aber, dass er dasselbe gerade beim Schmieden abgelegt hat, weil es ihm unbequem war.

3. Johann Freisigacker, 41 Jahre, Landwirth, Mörlenbach. Seit 7 Jahren rechter Leistenbruch, hühnereigross; das Bruchband hält den Bruch nicht zurück; die Bruchpforte ist für den Zeigefinger durchgängig. Links beginnender Leistenbruch. Es werden Injectionen gemacht am 1., 8., 15., u. 22. October 1877. Der Bruch tritt immer noch dann und wann unter dem Bruchband aus aber nicht mehr so stark. Im November wird ein neues Bruchband gekauft; dasselbe hält den Bruch gut zurück, drückt aber sehr stark. 11., 21: December 1876 jedesmal 2 Spritzen Alc. Nach der 2. Einspritzung subcutane Eiterung; 13. Januar 1877 Abscess geöffnet. 28. Januar Eiterung geheilt. Bruchpforte geschlossen; es wurde während der Eiterung das Bruchband getragen, wenn Patient ausser Bett war.

28. Januar links 2 Injectionen auf einmal. 10. Februar links starke Entzündung und Eiterung; Abscess wird geöfhnet. Ende Februar Eiterung geheilt.

4., 11., 18., u. 25. März rechts und links je eine Spritze. Vom Bruche ist bei Husten u. s. w. nichts mehr zu bemerken.

2., 8., u. 15. April 1877 beiderseits je eine Spritze. Der Richtung des Leistenkanals entsprechend hat sich rechts eine ungefähr 2 Linien dicke subcutane Verhärtung gebildet.

7. Mai ohne Bruchband von Mörlenbach ( 3 Stunden) zu Fuss gekommen; Bruch nicht heraus getreten, beim stärksten Husten nichts $\mathbf{m a}$ fühlen. Bruchpforten vollständig geschlossen.

13. Mai ebenso.

4. Adam Maurer der 3te, 30 Jahre alt, Hammelbach. Seit 14 Jahren rechter scrotaler Leistenbruch, kindskopfgross; der Daumen kann sehr bequem in die Bruchpforte geführt werden. Der Bruch ist leicht 'repo-

1) Diese Angabe ist nicht ganz richtig. Der Fehler beträgt aber nicht poll 1 Procent. 
nibel aber trotz Bruchband, welches zu schwach ist, fast immer ausgetreten. Ein neues starkes Bruchband schliesst gut.

Injectionen am 15., 20. u. 26. Februar, 9., 11., 18. u. 25. März, 2., 8., 15. u. 29. April 1877, fast immer 2 Spritzen in einer Sitzung, bisweilen drei.

21. Februar Bruch beim zu Bette gehen ausgetreten. Vom 26. Februar an Bruch nicht mehr ausgetreten.

18. März Bruchpforte geschlossen; man fühlt nur noch einen Alachen Ring.

25. März Bruchpforte geschlossen, aber beim Husten noch Andrang der Eingeweide fühlbar.

8. April beim stärksten Husten tritt nichts heraus.

29. April ebenso, Bruchpforte vollständig geschlossen.

In Betreff der Eiterung möchte ich ausdrücklich hervorheben, dass ich bei Patienten, welche sich an dem Wohnorte des behandelnden Arztes aufhalten, die Erregung subcutaner Eiterung durch reichliche Einspritzung von Alcohol und schnelle Wiederholung der Einspritzungen als Methode empfehlen möchte, weil der Heilungsvorgang viel schneller von Statten geht und weil bei einer subcutanen Eiterung keine Gefahr besteht.

Um öfteren Anfragen zu genïgen will ich die Art und Weise, wie ich die Injectionen ausführe, hier kurz beschreiben. Der Kranke lagert sich mit dem Bruchbande ganz horizontal, zieht die Schenkel an und nimmt nun erst das Bruchband ab. Dann suche ich mit dem Finger die Bruchpforte auf, aberzeuge mich genau, dass auch nicht der kleinste Theil des Bruches ausgetreten ist und steche nun ungefähr 1 Zoll vom Anfang der Bauchpforte entfernt die Nadel der Pravaz'schen Spritze unter die Haut in der Richtung auf die Bruchpforte hin. Ich lege in den verschiedenen Sitzungen die Einstichspunkte so, dass sie oberhalb des Poupart'schen Bandes einen Halbkreis um die Bauchpforte als Centrum beschreiben; die Spitze der Nadel wird immer nach der Bruchporte garichtet. Die Nadel wird gewöhnlich bis zur Hälfte ihrer Länge in die erhobene Hautfalte eingestochen; man muss darauf Acht geben, dass sie ordentlich in das Unterhautbindegewebe gelangt. Ist sie gut in das Unterhauthindegewebe eingefuihrt, so ist sie sehr leicht beweglich. Twu wartet man ungefähr eine Minute, um sich zu überzeugen, dass Kein Blut kommt; dann setzt oder schraubt man die Spritze auf und spritzt langsam den halben oder ganzen Inhalt derselben aus. Dann zieht man schnell die Nadel heraus, legt den Finger auf die Einstichsöfnung und befestigt das Bruchband sogleich wieder. Sollte die Flüssigkeit die Haut stark buckelförmig hervorgetrieben haben, so hält man mit dem Finger der einen Hand die Einstichsöffnung zu, mit der anderen IIand sucht man durch vorsichtiges Streichen und Reiben die Flüssigkeit zu vertheilen. Ist beim Einstich der Canulle Blut gekommen, so zieht man die Canille sogleich wieder heraus, reinigt sie sorgfialtig und sticht an einer anderen Stelle ein. Wird die vordere Wand des Leistenkanales beim Husten hervorgewölbt, so pflege ich auch über diese Stelle subcutane lnjectionen vorzunehmen, um die Wand zu stärken und weniger mechgiebig zu machen.

$$
\text { Na ch t rag. }
$$

Am 13. August hatte ich Gelegenheit den Kranken mit Namen Maurer wieder zu sehen. Derselbe hielt sich für vollständig geheilt und brachte mir einen neuen Bruchkranken. Bei der Untersuchung zeigte sich, dass selhst bei starkem Husten der Bruch nicht heraustrat aber dass die Bruchpforte für die Spitze des Zeigefingers zugänglich war. Vor der Behandlung ging der Daumen bequem tief in die Bruchpforte. Die Behandlung wird von neuem aufgenommen und werde ich nach Verlauf eines Jahres wieder darüber berichten.

Am 20. August untersuchte ich den Kranken Freisigacker wieder. Hier waren alle die subcutanen Verhärtungen verschwunden. Die vordere Wand des Leistenkanals giebt wieder mehr nach; es ist wieder deutlich eine Bruchpforte zu fühlen, in welcher man beim Husten den Andrang der Eingeweide finhlt. Patient hat wochenlang an einem sehr heftigen Husten gelitten. Ein Austritt des Bruches hat nie Statt gefunden. Patient will eine weitere Behandlung erst im Winter vornehmen lassen.

Beide Patienten müssen jetzt noch Bruchbänder tragen. 